\title{
The future is in our hands
}

\author{
C. Niek van Dijk
}

Published online: 10 July 2010

(c) The Author(s) 2010. This article is published with open access at Springerlink.com

The world around us is changing quickly and we must change with it. Persons and organizations that are not flexible and do not move with their surrounding will find it hard to survive.

This is true also for ESSKA.

The best way to keep ahead of things and be prepared for the future is to have a defined strategy. ESSKA was founded by a group of knee surgeons and defined its purpose in general and global terms in 1984. Sports Trauma was added in 1992, but without any in-depth discussions about the mission and goals of the organization. In the year 2002 the name changed to ESSKA 2000, but we did not change article 6 , which defines the purpose of the society. Likewise in 2008 when it was decided to change back to ESSKA, we kept our article 6 intact.

This does not mean that we have not done well. On the contrary, an increasing number of members, growth of the fellowship programme, a huge activity in our scientific committees and sections, increasing activities toward Eastern Europe, a well-organized professional Bureau in Luxemburg, the reorganized KSSTA Journal, a positive attitude toward the expanding subspecialties, increased contact with National Societies, a close relation with international societies like ISAKOS and a great and highly rewarded biannual congress with 2,200 Participants in Oslo.

But we went from decision to decision. We did not define our goals, objectives and action program in a structured manner. And what is more important we did not

C. N. van Dijk ( $\square)$

ESSKA President,

Department of Orthopedic Surgery,

Academic Medical Centre, P.O. Box 22660,

1100 DD Amsterdam, The Netherlands

e-mail: c.n.vandijk@amc.uva.nl prioritize the goals of the society. Given our limited resources, it is important to use our strength and to eliminate our weaknesses. My mission as president of ESSKA is to create a strategic plan for the future. But this is a team effort! I invite everybody to participate in the discussion. Out of these discussions, we will define our goals for the future. These goals will lead to a working plan with objectives and action programs. Our strategic plan will provide improved structure to the society and make it even stronger in the future.

ESSKA wants to raise the level of care in the field of Arthroscopy, Knee Surgery and Orthopaedic Sports Medicine and thus improve the quality of life and the mobility of our patients. ESSKA offers its members support in research and education. ESSKA aims to improve the communication and visibility on ESSKA activities and achievements and to improve the corporation between our members, national and international societies.

This could be the mission of ESSKA.

Politicians are generally not aware of the significance of the musculoskeletal diseases. This field is underrepresented and low ranked by politicians when decisions about financial support are made. Other medical fields have received much greater attention and resources, in spite of the fact that the treatment available is among the most efficient and cost effective!

With the increasing elderly population worldwide and the number of persons involved in sports increasing as well, the quantity in number of patients with joint problems will be encountered by quality in treatment. We must work on the public image using our reputation. We will work together with EFORT and EUCOMED to build a strategy toward the EU and Brussels.

For the upcoming 2 years apart from the making of this strategic plan the Board activities will be directed toward 
reinforcement of our professional office in Luxemburg and reinforcement of the KSSTA Journal. We are currently working on the reorganization of the journal, for instance moving the editorial office to the ESSKA headquarters. The page budget will increase, and after the summer a new and stronger Editorial Board will be announced. And, do not forget the journal's brand new website. The short-term goal is to establish the journal as one of leading organs in the field of Knee Surgery Sports Traumatology and Arthroscopy. An increased impact factor is our immediate goal. ESSKA will concentrate on all member countries including Eastern Europe and facilitate and strengthen the relationship with national societies. We find it important to accommodate all subspecialties under the ESSKA umbrella. A change of the by-laws will make it possible to accommodate sections like knee arthritis, the athlete's ankle and the athletes shoulder. We will stimulate independent societies and working groups which focus on Arthroscopy, Knee Surgery and Sports Traumatology to affiliate with ESSKA. Our members can benefit from the expertise within these groups and at the same time these groups can benefit from our professional organization, ESSKA standing, image, facilities, services and our journal!

ESSKA will concentrate on finding ways to be attractive for young members. ESSKA is a swinging society with sex appeal for the young.

We will work on new committee charges and rules for affiliated societies. Each board member is responsible for his own portfolio. Country society presidents will be involved as members at large in order to have a closer contact with the national societies. The site selection procedure for future ESSKA congresses will be reorganized, and we will find a way to work together with the well-established subspeciality organizations to synchronize major events.

We will work together with ISAKOS on e-learning and we will work on ESSKA best practices. In the members only section of our website, you will find Registration of Congress presentations and the ESSKA/ISAKOS Standard terminology. This important project currently includes standard terminology for pathology of all major joints. It will be extended to include muscle and tendon injuries as well. It is of utmost importance that we all speak the same scientific language. Springer will use this material as a starting and reference point for their new Encyclopedia on Sports Medicine and Arthroscopy.

How can we achieve all this? ESSKA is a strong and well-respected organization with an excellent potential among dedicated members. There is a lot of expertise and enthusiasm in our committees. The 6 free current concept books that you all received at the Biannual Oslo Conference are the result of voluntary scientific activity. The creativity, inspiration, energy and dedication among our members are enormous. Almost $20 \%$ of our members are currently active in of one of our committees or sections. ESSKA has always had strong and devoted leaders, but it is one of the major strength of ESSKA that most of our members are opinion leaders in their countries.

There is a lot of work to do, but I know it is possible because I am surrounded by a great organization. The professional administrative office with a fantastic connected and devoted staff is capable to execute an enormous amount of work in limited time. They are flexible and prepared to work at inconvenient hours when necessary. They are the backbone of our society.

ESSKA is a great and healthy society and I promise to move it forward.

Open Access This article is distributed under the terms of the Creative Commons Attribution Noncommercial License which permits any noncommercial use, distribution, and reproduction in any medium, provided the original author(s) and source are credited. 